\title{
DNA methylation: a permissive mark in memory formation and maintenance
}

\author{
Ana M.M. Oliveira \\ Department of Neurobiology, Interdisciplinary Center for Neurosciences (IZN), University of Heidelberg, \\ 69120 Heidelberg, Germany
}

\begin{abstract}
DNA methylation was traditionally viewed as a static mechanism required during cell fate determination. This view has been challenged and it is now accepted that DNA methylation is involved in the regulation of genomic responses in mature neurons, particularly in cognitive functions. The evidence for a role of DNA methylation in memory formation and maintenance comes from the increasing number of studies that have assessed the effects of manipulation of DNA methylation modifiers in the ability to form and maintain memories. Moreover, insights from genome-wide analyses of the hippocampal DNA methylation status after neuronal activity show that DNA methylation is dynamically regulated. Despite all the experimental evidence, we are still far from having a clear picture of how DNA methylation regulates long-term adaptations. This review aims on one hand to describe the findings that led to the confirmation of DNA methylation as an important player in memory formation. On the other hand, it tries to integrate these discoveries into the current views of how memories are formed and maintained.
\end{abstract}

It is now well established that gene transcription activation and de novo protein synthesis are required for long-term forms of neuronal plasticity and memory (Alberini and Kandel 2015; Benito and Barco 2015). Changes in the expression of growth factors, ion channels, ligand-gated receptors, and structural proteins are necessary to support long-lasting functional and structural changes within a neuronal circuit. This functional and structural remodeling is believed to underlie memory formation and maintenance.

An increasing amount of evidence has convincingly demonstrated that epigenetic mechanisms play an important role in cognitive functions through the regulation of transcriptional responses (Barrett and Wood 2008; Graff and Tsai 2013; Zovkic et al. 2013). Epigenetics include mechanisms of chromatin regulation via covalent modifications of the DNA, such as DNA methylation, hydroxymethylation, and demethylation (Suzuki and Bird 2008; Bhutani et al. 2011; Branco et al. 2012; Moore et al. 2013) as well as histone post-translational modifications (Strahl and Allis 2000).

DNA methylation was traditionally viewed as a static mechanism with important roles in transcription repression in cell fate determination, imprinting, female X-chromosome inactivation, and silencing of transposons during early development (Suzuki and Bird 2008). This view has been challenged and it is now accepted that DNA methylation plays also a critical role in the regulation of genomic responses in mature neurons. This review highlights the requirements for the enzymes responsible for DNA methylation and demethylation in memory encoding. In addition, it describes the data demonstrating dynamic changes in the methylation status of postmitotic neuronal DNA in response to experience. This review further aims to integrate these findings into the current views of how memories are formed and maintained.

Corresponding author: oliveira@nbio.uni-heidelberg.de Article is online at http://www.learnmem.org/cgi/doi/10.1101//m.042739. 116.

\section{Pharmacological and genetic evidence for DNA methylation in memory formation and maintenance}

Early findings from the Sun and Greenberg laboratories showed that DNA methylation and its reader methyl-CpG-binding protein 2 (MeCP2) are involved in the regulated expression of brainderived neurotrophic factor $(B d n f)$ upon neuronal activity in primary neuronal cultures (Chen et al. 2003; Martinowich et al. 2003). These studies provided the first hint that DNA methylation plays a role in the regulation of neuronal activity-dependent gene transcription and possibly in the mechanisms of synaptic plasticity. They were corroborated and further expanded by subsequent in vivo pharmacological and genetic studies targeted at the manipulation of DNA methylation processes that showed altered plasticity mechanisms such as long-term potentiation (LTP) and cognitive abilities.

\section{Pharmacological studies}

Pharmacological inhibition of DNA methyltransferases (Dnmts) consistently resulted in impairments in plasticity and memory formation. Hippocampal LTP induction and maintenance were impaired in the presence of the Dnmt inhibitors, zeburaline, and 5-aza-2-deoxycytidine (5-AZA) (Levenson et al. 2006). Also, amygdalar LTP was shown to be impaired by 5-AZA treatment (Monsey et al. 2011). Infusions into the amygdala of 5-AZA or RG108 (a nonnucleoside inhibitor of Dnmts) (Brueckner et al. 2005) affected memory-related neurophysiological responses in awake rats (Maddox et al. 2014). Similarly to its effects on synaptic plasticity, pharmacological inhibition of Dnmts impacted memory formation. Miller and Sweatt (2007) showed that infusions of zeburaline or 5-AZA into hippocampal area CA1, a region critical

(C) 2016 Oliveira This article is distributed exclusively by Cold Spring Harbor Laboratory Press for the first 12 months after the full-issue publication date (see http://learnmem.cshlp.org/site/misc/terms.xhtml). After 12 months, it is available under a Creative Commons License (Attribution-NonCommercial 4.0 International), as described at http://creativecommons.org/licenses/by$\mathrm{nc} / 4.0 /$. 
for memory formation, immediately after contextual fear conditioning training reduced rats' ability to form long-term memory (Miller and Sweatt 2007). These findings were confirmed in a study by the same group in which the authors showed that zeburaline or RG108 intra-CA1 infusions prior contextual fear conditioning training impairs long-term memory formation but not short-term memory (Lubin et al. 2008). Moreover, hippocampal zeburaline treatment decreased long-term, but not short-term place field stability (Roth et al. 2015). These studies have been extended to other forms of memory and brain regions. Intraamygdalar infusion of 5-AZA or RG108, for instance, induced long-term memory impairments in auditory fear conditioning without affecting short-term memory (Monsey et al. 2011; Maddox et al. 2014). In addition, hippocampal or cortical administration of RG108 impaired long-term memory in a spatial object recognition test (Mitchnick et al. 2015). Interestingly, DNA methylation has also been shown to be required for memory specificity in a form of conditioning in the honeybee (Biergans et al. 2012, 2016). Thus, DNA methylation appears to be a conserved mechanism required for long-term memory formation across brain regions and species. The selective effect on long-term memory further suggests that DNA methylation is involved in the regulation of learning-dependent gene transcription required for longterm memory formation.

The striking majority of studies have focused on the role of DNA methylation in memory formation; however, Miller et al. (2010) also investigated whether DNA methylation may also underlie the maintenance of memory. In this study, the authors focused on the anterior cingulate cortex (ACC), a brain region thought to hold the representation of remote memories upon their formation in the hippocampus (Frankland et al. 2004). The authors observed a persistent change in the methylation status of the memory suppressor gene calcineurin $(\mathrm{CaN})$ in the ACC after contextual fear conditioning that was associated with reduced CaN expression levels (Miller et al. 2010). Moreover, infusion of Dnmt inhibitors into the mouse ACC $30 \mathrm{~d}$ after training disrupted remote memory in a contextual fear conditioning task. These findings suggest the intriguing possibility that-in contrast to the processes underlying memory formation in the hippocampus, where a short-term up-regulation of Dnmt activity is requiredthe maintenance of memory via the ACC requires long-lasting DNA methylation changes and continuous Dnmt activity (Miller et al. 2010).

\section{Genetic studies}

The pharmacological evidence supporting a role for DNA methylation in memory formation and maintenance has been corroborated by genetic approaches targeted at disrupting the function of DNA methyltransferases. For example, two studies used Dnmt1 and Dnmt3a conditional knockout mice to address the role of these enzymes in memory formation (Feng et al. 2010; Morris et al. 2014). In the conditional knockout mouse used in both studies, the gene deletion is restricted to the forebrain and to the postnatal age. Feng and colleagues found that only in the absence of both Dnmt 1 and Dnmt3a did the mice exhibit memory and LTP impairments. In contrast, Morris et al. found that knockout of Dnmt3a but not Dnmt1 elicited cognitive impairments. The reason for the discrepancy between the two studies is not clear. However, differences in the gender and age of the mice used and the genetic background might account for the distinct findings. In other studies, temporally and spatially controlled genetic manipulations have confirmed a role for Dnmt3a in hippocampus-dependent long-term memory formation (Oliveira et al. 2012, 2015; Mitchnick et al. 2015). The Dnmt3a genomic locus contains two genes, Dnmt3a1 and Dnmt3a2: the promoter of
Dnmt3a2 is located in the 6th intron of Dnmt3a and gives rise to a transcript encoding the Dnmt3a2 protein, which is identical to Dnmt3a1 except that it lacks 219 amino acids at its N-terminus (Chen et al. 2002). Dnmt3a2 is a neuronal activity-regulated immediate early gene whose expression is strictly dependent on NMDA receptor activation. In contrast, Dnmt3a1 appears to be expressed at higher levels, and its expression is not regulated by neuronal activity (Oliveira et al. 2012). Other studies have observed the learning-dependent activation of Dnmt3a expression. However, the isoform being analyzed was not distinguished (Levenson et al. 2006; Miller and Sweatt 2007; Monsey et al. 2011; Morris et al. 2014; Mitchnick et al. 2015).

Dnmt3a2 knockdown in the adult mouse hippocampus impairs hippocampal long-term memory formation and extinction (Oliveira et al. 2012, 2015). Moreover, basal and learning-induced Dnmt3a2 expressions are reduced in the aging hippocampus and reestablishing Dnmt3a2 levels rescues aging-dependent cognitive decline (Oliveira et al. 2012). Furthermore, a facilitating effect of Dnmt3a2 in cognitive function was not only observed in aged mice (Oliveira et al. 2012) but also in young adult cognitively normal mice (Oliveira et al. 2015). Whether Dnmt3a1 also plays a role in memory formation remains to be investigated.

Interestingly, Mitchnick and co-authors found a dissociation in the function of the different Dnmts between the hippocampus and the perirhinal cortex. More specifically, hippocampal knockdown of Dnmt3a caused long-term memory deficits in an objectplace recognition test. In contrast, knockdown of Dnmt1 in the perirhinal cortex, but not of Dnmt3a or Dnmt3b, caused longterm memory impairments (Mitchnick et al. 2015). These results suggest that different epigenetic mechanisms may operate differently within distinct brain regions during long-term memory formation, and highlights the need to analyze each region individually.

Taken together, pharmacological and genetic evidence emerging from different laboratories consistently showed that inhibition of Dnmt function, and particularly that of Dnmt3a, impairs hippocampal long-term plasticity and memory formation. Thus, the activity of Dnmts appears to be permissive for long-term memory formation. These findings appear counterintuitive at first given the view that DNA methylation of promoter regions is associated with transcriptional repression, according to which blocking DNA methylation should enhance, not impair, memory formation. However, the newly emerging picture is that the function of DNA methylation is dependent on the genomic location. How DNA methylation regulates genomic responses in the context of plasticity is not totally understood.

\section{DNA methylation and expression of plasticity-related genes}

Given the function of DNA methylation in transcriptional regulation, several studies have focused on the role of DNA methylation in regulating the expression of memory-related genes during long-term memory formation. DNA methylation changes in these genes upon learning have indeed been identified (Miller and Sweatt 2007; Lubin et al. 2008; Miller et al. 2010; Mizuno et al. 2012). These included both de novo methylation and demethylation, demonstrating that DNA methylation is dynamic, and providing evidence for the existence of active demethylation in postmitotic cells. Memory formation requires both the activation of memory promoting genes and the inhibition of memory suppressor genes (Abel and Kandel 1998; Abel et al. 1998), and DNA methylation/demethylation has been proposed as a potential molecular mechanism for achieving this dual regulation. In particular, pioneer work from the Sweatt laboratory reported promoter demethylation in genes required for memory formation, 
such as reelin, but also the methylation of promoters of memory suppressor genes such as the phosphatase PP1 (Miller and Sweatt 2007).

Later findings from Miller et al. (2010) suggest that this mechanism may not be restricted to memory formation but may also be involved in regulating memory persistence. Specifically, the authors observed a significant persistent increase in the methylation of the memory suppressor gene $\mathrm{CaN}$ in the ACC after contextual fear conditioning.

An increasing body of evidence convincingly demonstrates the existence of active DNA demethylation in postmitotic neurons. Recently, it has been shown that the ten-eleven-translocation (Tet) family of dioxygenases is involved in DNA demethylation via the formation of an intermediate, 5-hydroxymethylcytosine $(5 \mathrm{hmC})$, in the adult mouse brain (Guo et al. $2011 \mathrm{~b}$ ). Interestingly, $5 \mathrm{hmC}$ has also been proposed to be an epigenetic mark in its own right (Branco et al. 2012; Li et al. 2014). Consistent with an important role for Tet enzymes in cognitive function, a few studies have already demonstrated memory and extinction impairments upon interference with Tet family members (Kaas et al. 2013; Rudenko et al. 2013; Li et al. 2014). Other molecules proposed to be involved in active DNA demethylation include members of the growth arrest and DNA-inducible 45 (Gadd45) family and Methyl-CpG-binding domain protein 4 (Mbd4) (for recent reviews on mechanisms of active DNA demethylation see Gavin et al. 2013; Li et al. 2013; Lister and Mukamel 2015). Gadd45b and -g are known to be regulated by neuronal activity and learning (Ma et al. 2009; Leach et al. 2012; Sultan et al. 2012). There is also indication from two studies that used Gadd45b global knockout mice (Gupta et al. 2005) that this putative demethylase plays a role in learning and memory (Leach et al. 2012; Sultan et al. 2012). Because the two studies obtained contrasting results, however, it is not clear whether Gadd45b facilitates or constrains fear memory formation.

\section{Genome-wide analysis of DNA methylation changes triggered by neuronal activity}

Most studies examining DNA methylation changes after neuronal activity or learning have predominantly focused on the expression analysis of preselected genes and in the methylation analysis of their promoters. Genome-wide studies show that this type of analysis is rather limited, because most activity-regulated changes occur outside gene promoters (Guo et al. 2011a; Halder et al. 2016). Activity-dependent changes in DNA methylation in the adult dentate gyrus have been shown to be enriched at both intergenic and intronic regions (Guo et al. 2011a). This finding was recently confirmed by another study that examined DNA methylation changes in the hippocampal CA1 region and the ACC after contextual fear conditioning (Halder et al. 2016). Thus, genomewide analysis appears necessary to obtain a clearer picture of how DNA methylation plays a role in memory formation. In agreement with the genetic evidence that the enzymes responsible for de novo DNA methylation or demethylation are required for memory formation, and consistent with the idea that the two processes are necessary for long-term neuronal adaptations, these studies also demonstrated rapid de novo DNA methylation and demethylation in the hippocampus in response to increased neuronal activity (Guo et al. 2011a) or fear conditioning (Halder et al. 2016). Halder and colleagues found that learning-induced DNA methylation changes significantly colocalized with H3K27ac regions, indicating that at least some of these changes are targeted to cis-regulatory regions. In agreement with a possible role in regulating gene expression, a fraction of the genes that are differentially expressed after fear conditioning were also differentially methylated. In this study, DNA methylation analysis was performed in the CA1 region of the hippocampus, an area critical for memory formation, and in the ACC, a region important for long-term memory storage. Consistent with these functions, significant DNA methylation changes were identified in CA1 only at early time points after learning $(1 \mathrm{~h})$ and not at $4 \mathrm{wk}$. In contrast, in the ACC, DNA methylation changes were detected at both time points. These findings are in agreement with the study of Miller et al. (2010) that found persistent changes in the DNA methylation status of the CaN gene promoter in ACC after contextual fear conditioning. Interestingly, in the study by Halder et al. (2016), gene ontology analysis indicated that the differentially methylated and expressed genes in CA1 were enriched for the functional categories "ion channels" and "transcription regulation." At 4 wk after fear conditioning, differentially methylated and expressed genes in the ACC were enriched for functional categories associated with morphology regulation. These findings may indicate that DNA methylation mechanisms regulate synaptic transmission and gene transcription during hippocampal memory formation and cortical morphological arrangements required for memory maintenance.

Both the Guo et al. (2011a) and Halder et al. (2016) studies found that activity-dependent changes in DNA methylation were also associated with the generation of alternative splice variants. This is in agreement with a previously established role for DNA methylation in RNA splicing regulation (Shukla et al. 2011) and suggests that this mechanism may also play a role during memory formation.

Although DNA methylation changes were enriched in intergenic and intragenic regions (Guo et al. 2011a; Halder et al. 2016) and although they colocalized with putative cis-regulatory regions (Halder et al. 2016), these methylation changes did not always correlate with gene transcription changes (Guo et al. 2011a; Li et al. 2014), indicating that the role played by neuronal activity triggered de novo DNA methylation and demethylation may not only reside in direct regulation of expression of associated genes (Guo et al. 2011a) or even always be associated with transcriptional changes. Moreover, DNA methylation changes may precede or persist beyond the time when transcriptional changes are observed (Li et al. 2014). As previously proposed (Guo et al. 2011a; Baker-Andresen et al. 2013), an intriguing possibility is that DNA methylation changes, in addition to directly regulating gene expression at some loci, may also be responsible for creating a primed, more permissive environment for subsequent genomic regulation. In such a scenario, a "primed genome" could be more readily activated, inducing stronger or faster transcriptional responses. Priming mechanisms could include, for instance, setting the environment for transcription factor binding (Domcke et al. 2015; Schubeler 2015). Also, de novo DNA methylation could provide a substrate for subsequent epigenetic marks. Consistent with this idea, it was recently observed that Dnmt3a knockout leads to reductions in both $5 \mathrm{mC}$ and $5 \mathrm{hmC}$, suggesting that de novo DNA methylation generates the $5 \mathrm{mC}$ substrate for the activity of enzymes responsible for DNA hydroxymethylation, such as Tets (Colquitt et al. 2014). Moreover, an interplay between DNA methylation and histone post-translational modifications (Vaissiere et al. 2008) may also occur. Evidence for such interaction during memory consolidation already exists (Miller et al. 2008; Monsey et al. 2011). Miller et al. (2008) and Monsey et al. (2011) showed that pharmacological inhibition of Dnmts impaired trainingdependent histone $\mathrm{H} 3$ acetylation, and that DNA methylation and histone acetylation may work in concert during fear memory consolidation in the hippocampus and amygdala, respectively.

In order to thoroughly analyze the interdependence and timecourse of the various epigenetic marks, it would be interesting to perform a detailed temporal analysis after a learning event 
of the various epigenetic marks in conjunction with transcription factor occupancy and gene expression studies. As technology stands, the costs and labor associated with such a study are unfortunately prohibitive.

\section{Possible roles for DNA methylation in memory formation and maintenance}

\section{Cellular-level memory consolidation}

The formation of long-term memory is strictly dependent on the activation of gene transcription and de novo protein synthesis (Alberini and Kandel 2015). A learning event, such as exposure to a new environment or training in a fear conditioning test, triggers rapid activation of transcription in the hippocampus. This early transcriptional response, which occurs within the first hour after the learning stimulus, is dominated by the expression of immediate early genes (IEGs). The expression of IEGs is dependent on constitutively expressed transcription factors (TFs) such as cAMP responsive element binding protein (Creb), myocyte enhancer factor-2 (Mef2), and serum response factor (SRF) that are activated by post-translational modifications downstream from signaling cascades regulated by neuronal stimulation. Among the rapidly regulated IEGs are a number of TFs, including FBJ osteosarcoma oncogene (c-Fos), neuronal PAS domain protein 4 (Npas4), and early growth response 1 (Egr1), that are responsible for driving a secondary transcriptional response and regulating the expression of effector genes. The effectors genes, in turn, are thought to be required for the plastic changes associated with learning and memory (Benito and Barco 2015). Both pharmacological inhibition of the first transcriptional wave (for review, see Korzus 2003) and interference with the function of activity-regulated TFs induce robust impairments in memory formation (Jones et al. 2001; Fleischmann et al. 2003; Katche et al. 2010; Ramamoorthi et al. 2011), demonstrating the importance of this step. The high relevance of this first event for the formation of memories has resulted in an almost exclusive research focus on this early transcriptional response. However, a few studies have also described a second wave of expression (8-24 h after learning) for some activity-regulated genes in the hippocampus (Arc, cFos, Egr1, $B d n f$ ) (Igaz et al. 2002; Bekinschtein et al. 2007; Katche et al. 2010; Nakayama et al. 2015). Interestingly, only those memories that are persistent exhibit a second wave of IEG expression (Katche et al. 2010), and inhibition of this wave impairs memory maintenance, but not memory formation (Bekinschtein et al. 2007; Katche et al. 2010; Nakayama et al. 2015). Together, these findings suggest that additional rounds of transcription and protein synthesis may be necessary for the persistence of memory. Moreover, although merely speculative due to the lack of experimental evidence, the multiple rounds of transcription acti- vation may reflect the communication between the hippocampus and neocortical regions that is believed to occur during the process of systems-level memory consolidation (see below).

As described in the above sections, pharmacological and genetic manipulation of DNA methylation modifiers demonstrates their requirement in memory formation and maintenance. Moreover, neuronal activity induces genome-wide de novo DNA methylation and demethylation in the adult mouse hippocampus. Therefore, it is now well accepted that DNA methylation mechanisms play a role in memory formation and maintenance. However, a clear picture of how DNA methylation regulates memory processes is still elusive. Bringing together the current knowledge of the mechanisms underlying memory formation and maintenance and the findings concerning DNA methylation, I propose that DNA methylation players that are activated by neuronal activity (including Dnmt $3 a 2$, Gadd $45 \mathrm{~b} / \mathrm{g}$, and possibly others) could have at least a twofold role in memory formation and maintenance in the hippocampus. They could, on the one hand, generate a primed and more permissive epigenome state that could facilitate future transcriptional responses and on the other hand, directly regulate the expression of genes that set the strength of the neuronal network connectivity, this way altering the probability of reactivation of the same network (Fig. 1).

In the first wave of learning-dependent transcription, the expression of the genes coding for Dnmt3a2 (Oliveira et al. 2012; DVC Brito and AMM Oliveira, unpubl.), Gadd45b/g (Leach et al. 2012; Sultan et al. 2012; DVC Brito and AMM Oliveira, unpubl.),

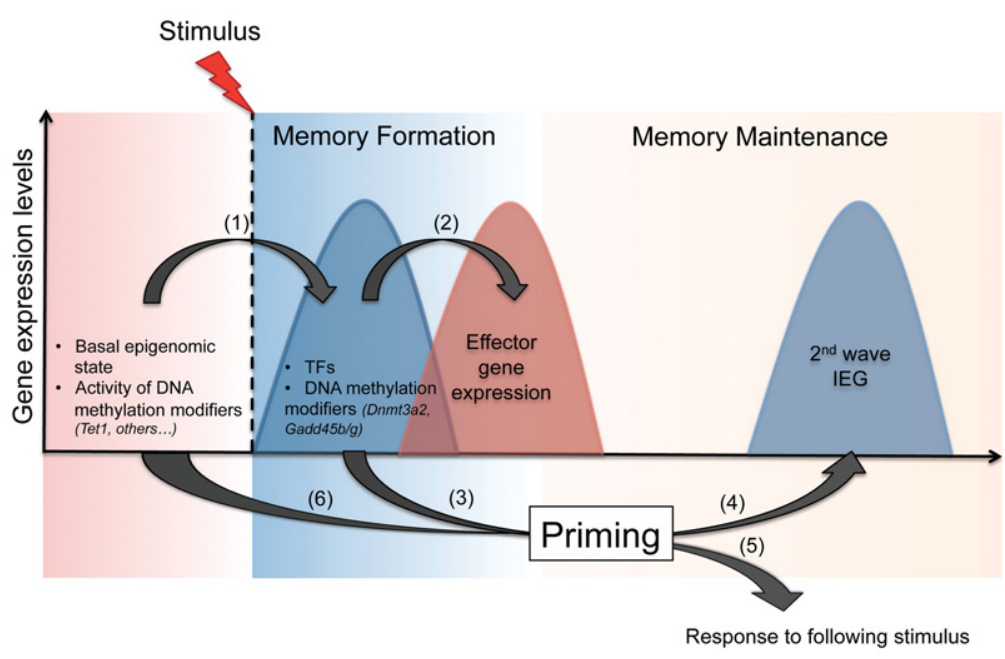

Figure 1. Hypothetical model for the regulation of hippocampal transcriptional responses during memory formation and maintenance by DNA methylation-dependent mechanisms. Gene transcription activation and de novo protein synthesis are necessary for the formation and maintenance of memory. (1) Following a learning stimulus, an initial transcription wave is induced. The basal epigenetic state of the neuron likely dictates the permissiveness for the activation of the first wave of transcription. For instance, DNA demethylases (such as Tet1 [Rudenko et al. 2013] and possibly others) may be required to hold the promoter and/or enhancer of activity-regulated genes in a hypomethylated state in order to permit rapid activation of transcription. (2) The first wave of transcription includes the up-regulated expression of activity-dependent transcription factors (TFs) (cFos, Npas4, Egr1) and DNA methylation modifiers (Dnmt3a2 (Oliveira et al. 2012), Gadd45 b/g (Ma et al. 2009; Leach et al. 2012; Sultan et al. 2012), and possibly others). These TFs and DNA methylation modifiers may work in concert to regulate the expression of downstream effector molecules. (3) In addition to regulating early learningdriven transcriptional responses, DNA methylation players may also modify the epigenome, priming it (4) for later waves of gene expression (for instance, second waves of IEG expression, proposed to be important for memory maintenance), or (5) for responses triggered by subsequent stimulations (such as memory recall or the presentation of a new stimulus). (6) Finally, DNA methylation players, the expression of which are not regulated by neuronal activity, could instead be subject to regulation at the level of activity, stability, or subcellular localization (possibly via post-translational modifications), thus providing for another contribution to the learning-triggered transcription responses and/or epigenome priming. TFs, transcription factors; IEG, immediate early gene. 
and activity-regulated TFs (e.g., c-Fos, Npas4, Egr1) is activated simultaneously. Activity-regulated TFs and epigenetic modifiers may then act in concert during the regulation of the secondary transcriptional responses driven by these TFs (Fig. 1, step 2). Plausible mechanisms include establishing the environment for the binding of the activity-regulated TFs, transcription facilitation by de novo DNA methylation within target gene bodies, active DNA demethylation, or the establishment of $5 \mathrm{hmC}$ marks. Moreover, the activity-regulated epigenetic molecules could prime the genome in a way that would render permissive for the second wave of IEG transcription and further hypothetical rounds of transcription possibly through similar mechanisms (Fig. 1, steps $3,4,5$ ). It would be interesting to investigate if the activity-regulated epigenetic molecules are induced in the later hippocampal transcriptional waves that underlie memory persistence. This could function as a propagation mechanism to ensure efficient transcriptional responses necessary for the maintenance of memory.

Regarding the regulation of the early transcriptional response triggered by learning, it is highly unlikely that this response is dependent on the pool of activity-regulated epigenetic modifiers. The activation of expression of IEGs and epigenetic modifiers occurs simultaneously; therefore, interdependency is not possible. Thus, it is likely that the first transcriptional wave depends on the resting epigenomic state of the neuron or on the activity of the basal pool of epigenetic modifiers (Fig. 1, step 1). Active DNA demethylation during basal conditions could be required for the maintenance of TF-binding sites (such as promoters and enhancers) in a hypomethylated state (Rudenko et al. 2013). This would allow for a rapid transcriptional response upon neuronal stimulation. Another intriguing possibility is that the activity or even the sub-cellular localization of the DNA methylation writers and erasures-rather than their expression levels-are regulated by neuronal activity. In such a scenario, the rapid regulation of DNA methylation players could play a role in the regulation of the transcriptional responses triggered by neuronal stimulation (Fig. 1, steps 1, 6). One could envisage that posttranslational modifications could serve as a molecular mechanism for such fast regulation, and regulation by post-translational modifications of Dnmts has been shown in other cell types (Denis et al. 2011). Whether this also occurs in neurons has never been investigated.

On a network level, it is now believed that a memory trace is allocated to a subpopulation of neurons (neuronal ensembles) and that its consolidation is associated with the strengthening of the synaptic connections between this set of neurons (Josselyn et al. 2015; Ryan et al. 2015). These changes in connectivity are thought to increase the likelihood that the same neuronal population will be reactivated during the recall of the memory. A role for DNA methylation in the formation and stabilization of neuronal ensembles associated with a particular memory has never been investigated. It is tempting to speculate that DNA methylation is involved in the modulation of the strength of synaptic connections within the neuronal ensemble and consequently sets the likelihood for reactivation of the same neuronal population to occur during memory recall. As mentioned above, DNA methylation changes in the hippocampus triggered by neuronal activity or learning preferentially occur at genes that regulate signal transduction pathways and synaptic function and were also associated with the generation of alternative splice variants (Guo et al. 2011a; Halder et al. 2016). It is therefore plausible that the gene pool controlled by de novo DNA methylation and demethylation confers unique functional properties to neurons that allow them to alter their connectivity and excitability, hence determining the likelihood of their reactivation.

\section{Systems-level memory consolidation}

Although much is known about the mechanisms underlying memory formation, the mechanisms underlying maintenance and long-term storage of memories are much less explored. It has been postulated that neocortical regions are responsible for the long-term storage of information (Frankland et al. 2004). Through a mechanism known as systems consolidation, it is thought that recent memories are initially encoded in the hippocampus and neocortex and, with the passage of time, become independent of the hippocampus. The hippocampus is thought to guide the gradual stabilization of the information in the neocortex through hippocampal-cortical communication (Squire et al. 2015). Recently, the neural replay of the learning activity pattern during sleep phases was proposed as a neural mechanism underlying this dialogue ( $\mathrm{O}^{\prime}$ Neill et al. 2008). However, molecular correlates of systems-level memory consolidation are largely unknown. Lesburgueres et al. (2011) suggested that a cortical "tagging process," which may be epigenetic in nature, occurs at the time of learning and facilitates the hippocampal-cortical communication necessary for the stabilization and restructuring of the neocortex during remote memory storage (Lesburgueres et al. 2011). The authors further suggested that cortical synaptic tags may function as early and persistent marks of activity that are necessary to ensure the progressive rewiring of cortical networks that underlies remote memory storage. In support of the idea that epigenetic mechanisms may be involved in the setting of synaptic tags, the authors observed increased acetylation of histone $\mathrm{H} 3$ in the cortex and demonstrated that increasing histone acetylation (through inhibition of histone deacetylases) in the relevant cortical region at an early phase of memory consolidation improved the "tagging process" and provided for enhanced remote memory. These findings suggest that histone acetylation facilitated the expression of putative molecular tags that could potentially support the stabilization and restructuring of memory-associated cortical networks. It is tempting to speculate that the maintenance of expression of these cortical tags depends also on Dnmt activity. This way, in agreement with the study from Miller et al. (2010), inhibiting Dnmt activity in the anterior cingulate cortex would impair remote memory maintenance. Intriguingly, Halder et al. (2016) recently showed that $1 \mathrm{~h}$ after contextual fear conditioning training DNA methylation changes occur in both the CA1 region of the hippocampus and the ACC. At $4 \mathrm{wk}$ after training, a time point that corresponds to remote memory, DNA methylation changes are still present in the ACC, but not in the hippocampus. Moreover, in the ACC, genes that were differentially methylated and expressed were functionally associated with structural changes. These findings provide support for a role of DNA methylation in the cortical rewiring necessary for stabilization of remote memory. Although the role of DNA methylation in systems-level consolidation has only been assessed in two studies (Miller et al. 2010; Halder et al. 2016) the correlation between the spatiotemporal pattern of DNA methylation changes and the systems-level consolidation theory is striking. As already proposed by the authors, DNA methylation could represent the molecular mnemonic substrate in memory formation and maintenance.

\section{Conclusions and open questions}

It appears now consensual that DNA methylation plays a central role in cognitive function. The manipulation of DNA methylation-related mechanisms consistently impacts memory processes. In light of the current literature, DNA methylation seems to regulate the expression of genes with relevant functions in neuronal transmission and structure in brain regions critical for memory. 
Moreover, the permissive role of DNA methylation-related mechanisms may also involve the priming of the neurons' epigenome for transcriptional responses during consolidation and/or responses to subsequent stimuli. However, this hypothesis still requires further experimental validation. Several gaps in the understanding of how DNA methylation regulates cognitive function still exist. For instance, it is not known how specificity is achieved, specifically how DNA methyltransferases or demethylases are targeted to specific genomic sites. Studies suggest that noncoding RNAs (Mohammad et al. 2012; Rajasethupathy et al. 2012) or chromatin marks (Ooi et al. 2007; Otani et al. 2009; Zhang et al. 2010) may be responsible for that targeting, but these mechanisms are still far from being understood. Further, it remains to be investigated whether DNA methylation occurs in genomic locations that undergo histone post-translational modifications upon learning. Are epigenetic mechanisms in general and DNA methylation in particular involved in the allocation of a memory trace to a subset of neurons? Does the epigenomic state of a neuron determine the recruitment of that neuron to a memory ensemble? Are DNA methylation changes in neocortical regions sustained for the duration of a particular memory? If so, how does DNA methylation regulate/allow for the integration of multiple memories?

Besides the proven participation of DNA methylation in cognitive mechanisms, dysregulation of the same processes have also been shown to occur in pathological conditions, such as neurodevelopmental (Pohodich and Zoghbi 2015) and neurodegenerative diseases (De Jager et al. 2014), psychiatric disorders (Gavin and Sharma 2010), drug addiction (LaPlant et al. 2010; Day et al. 2013), and chronic pain (Denk and McMahon 2012). This underscores the importance of further investigating and building a clearer picture of how DNA methylation regulates long-term adaptations.

\section{Acknowledgments}

The author thanks David Brito, Kübra Gülmez, Özlem Demir, and Anna M. Hagenston for helpful comments on the manuscript. This work was supported by grants from the German Research Foundation/Deutsche Forschungsgemeinschaft (DFG): SFB 1134 (Project C1) and an Emmy Noether grant (OL 437/1-1).

\section{References}

Abel T, Kandel E. 1998. Positive and negative regulatory mechanisms that mediate long-term memory storage. Brain Res Brain Res Rev 26: 360-378.

Abel T, Martin KC, Bartsch D, Kandel ER. 1998. Memory suppressor genes: inhibitory constraints on the storage of long-term memory. Science 279: $338-341$.

Alberini CM, Kandel ER. 2015. The regulation of transcription in memory consolidation. Cold Spring Harb Perspect Biol 7: a021741.

Baker-Andresen D, Ratnu VS, Bredy TW. 2013. Dynamic DNA methylation: a prime candidate for genomic metaplasticity and behavioral adaptation. Trends Neurosci 36: 3-13.

Barrett RM, Wood MA. 2008. Beyond transcription factors: the role of chromatin modifying enzymes in regulating transcription required for memory. Learn Mem 15: 460-467.

Bekinschtein P, Cammarota M, Igaz LM, Bevilaqua LR, Izquierdo I, Medina JH. 2007. Persistence of long-term memory storage requires a late protein synthesis- and BDNF-dependent phase in the hippocampus. Neuron 53: 261-277.

Benito E, Barco A. 2015. The neuronal activity-driven transcriptome. Mol Neurobiol 51: 1071-1088.

Bhutani N, Burns DM, Blau HM. 2011. DNA demethylation dynamics. Cell 146: $866-872$.

Biergans SD, Jones JC, Treiber N, Galizia CG, Szyszka P. 2012. DNA methylation mediates the discriminatory power of associative long-term memory in honeybees. PLoS One 7: e39349.

Biergans SD, Galizia CG, Reinhard J, Claudianos C. 2016. Corrigendum: Dnmts and Tet target memory-associated genes after appetitive olfactory training in honey bees. Sci Rep 6: 21656.
Branco MR, Ficz G, Reik W. 2012. Uncovering the role of 5-hydroxymethylcytosine in the epigenome. Nat Rev Genet 13: 7-13.

Brueckner B, Garcia Boy R, Siedlecki P, Musch T, Kliem HC, Zielenkiewicz P, Suhai S, Wiessler M, Lyko F. 2005. Epigenetic reactivation of tumor suppressor genes by a novel small-molecule inhibitor of human DNA methyltransferases. Cancer Res 65: 6305-6311.

Chen T, Ueda Y, Xie S, Li E. 2002. A novel Dnmt3a isoform produced from an alternative promoter localizes to euchromatin and its expression correlates with active de novo methylation. J Biol Chem 277: 38746-38754.

Chen WG, Chang Q, Lin Y, Meissner A, West AE, Griffith EC, Jaenisch R, Greenberg ME. 2003. Derepression of BDNF transcription involves calcium-dependent phosphorylation of MeCP2. Science 302: 885-889.

Colquitt BM, Markenscoff-Papadimitriou E, Duffie R, Lomvardas S. 2014. Dnmt3a regulates global gene expression in olfactory sensory neurons and enables odorant-induced transcription. Neuron 83: 823-838.

Day JJ, Childs D, Guzman-Karlsson MC, Kibe M, Moulden J, Song E, Tahir A, Sweatt JD. 2013. DNA methylation regulates associative reward learning. Nat Neurosci 16: 1445-1452.

De Jager PL, Srivastava G, Lunnon K, Burgess J, Schalkwyk LC, Yu L, Eaton ML, Keenan BT, Ernst J, McCabe C, et al. 2014. Alzheimer's disease: early alterations in brain DNA methylation at ANK1, BIN1, RHBDF2 and other loci. Nat Neurosci 17: 1156-1163.

Denis H, Ndlovu MN, Fuks F. 2011. Regulation of mammalian DNA methyltransferases: a route to new mechanisms. EMBO Rep 12: $647-656$.

Denk F, McMahon SB. 2012. Chronic pain: emerging evidence for the involvement of epigenetics. Neuron 73: $435-444$.

Domcke S, Bardet AF, Adrian Ginno P, Hartl D, Burger L, Schubeler D. 2015. Competition between DNA methylation and transcription factors determines binding of NRF1. Nature 528: 575-579.

Feng J, Zhou Y, Campbell SL, Le T, Li E, Sweatt JD, Silva AJ, Fan G. 2010. Dnmt1 and Dnmt3a maintain DNA methylation and regulate synaptic function in adult forebrain neurons. Nat Neurosci 13: 423-430.

Fleischmann A, Hvalby O, Jensen V, Strekalova T, Zacher C, Layer LE, Kvello A, Reschke M, Spanagel R, Sprengel R, et al. 2003. Impaired long-term memory and NR2A-type NMDA receptor-dependent synaptic plasticity in mice lacking c-Fos in the CNS. J Neurosci 23: 9116-9122.

Frankland PW, Bontempi B, Talton LE, Kaczmarek L, Silva AJ. 2004. The involvement of the anterior cingulate cortex in remote contextual fear memory. Science 304: 881-883.

Gavin DP, Sharma RP. 2010. Histone modifications, DNA methylation, and schizophrenia. Neurosci Biobehav Rev 34: 882-888.

Gavin DP, Chase KA, Sharma RP. 2013. Active DNA demethylation in post-mitotic neurons: a reason for optimism. Neuropharmacology 75: $233-245$.

Graff J, Tsai LH. 2013. Histone acetylation: molecular mnemonics on the chromatin. Nat Rev 14: 97-111.

Guo JU, Ma DK, Mo H, Ball MP, Jang MH, Bonaguidi MA, Balazer JA, Eaves HL, Xie B, Ford E, et al. 2011a. Neuronal activity modifies the DNA methylation landscape in the adult brain. Nat Neurosci 14: 1345-1351.

Guo JU, Su Y, Zhong C, Ming GL, Song H. 2011b. Hydroxylation of 5-methylcytosine by TET1 promotes active DNA demethylation in the adult brain. Cell 145: 423-434.

Gupta M, Gupta SK, Balliet AG, Hollander MC, Fornace AJ, Hoffman B, Liebermann DA. 2005. Hematopoietic cells from Gadd45a- and Gadd45b-deficient mice are sensitized to genotoxic-stress-induced apoptosis. Oncogene 24: 7170-7179.

Halder R, Hennion M, Vidal RO, Shomroni O, Rahman RU, Rajput A, Centeno TP, van Bebber F, Capece V, Vizcaino JC, et al. 2016. DNA methylation changes in plasticity genes accompany the formation and maintenance of memory. Nat Neurosci 19: 102-110.

Igaz LM, Vianna MR, Medina JH, Izquierdo I. 2002. Two time periods of hippocampal mRNA synthesis are required for memory consolidation of fear-motivated learning. J Neurosci 22: 6781-6789.

Jones MW, Errington ML, French PJ, Fine A, Bliss TV, Garel S, Charnay P, Bozon B, Laroche S, Davis S. 2001. A requirement for the immediate early gene Zif268 in the expression of late LTP and long-term memories. Nat Neurosci 4: 289-296.

Josselyn SA, Kohler S, Frankland PW. 2015. Finding the engram. Nat Rev 16: $521-534$

Kaas GA, Zhong C, Eason DE, Ross DL, Vachhani RV, Ming GL, King JR, Song H, Sweatt JD. 2013. TET1 controls CNS 5-methylcytosine hydroxylation, active DNA demethylation, gene transcription, and memory formation. Neuron 79: 1086-1093.

Katche C, Bekinschtein P, Slipczuk L, Goldin A, Izquierdo IA, Cammarota M, Medina JH. 2010. Delayed wave of c-Fos expression in the dorsal hippocampus involved specifically in persistence of long-term memory storage. Proc Natl Acad Sci 107: 349-354. 
Korzus E. 2003. The relation of transcription to memory formation. Acta Biochim Pol 50: $775-782$.

LaPlant Q, Vialou V, Covington HE III, Dumitriu D, Feng J, Warren BL, Maze I, Dietz DM, Watts EL, Iniguez SD, et al. 2010. Dnmt3a regulates emotional behavior and spine plasticity in the nucleus accumbens. Nat Neurosci 13: 1137-1143.

Leach PT, Poplawski SG, Kenney JW, Hoffman B, Liebermann DA, Abel T, Gould TJ. 2012. Gadd45b knockout mice exhibit selective deficits in hippocampus-dependent long-term memory. Learn Mem 19: 319-324.

Lesburgueres E, Gobbo OL, Alaux-Cantin S, Hambucken A, Trifilieff P, Bontempi B. 2011. Early tagging of cortical networks is required for the formation of enduring associative memory. Science 331: 924-928.

Levenson JM, Roth TL, Lubin FD, Miller CA, Huang IC, Desai P, Malone LM, Sweatt JD. 2006. Evidence that DNA (cytosine-5) methyltransferase regulates synaptic plasticity in the hippocampus. J Biol Chem 281: 15763-15773.

Li X, Wei W, Ratnu VS, Bredy TW. 2013. On the potential role of active DNA demethylation in establishing epigenetic states associated with neural plasticity and memory. Neurobiol Learn Mem 105: 125-132.

Li X, Wei W, Zhao QY, Widagdo J, Baker-Andresen D, Flavell CR, D'Alessio A, Zhang Y, Bredy TW. 2014. Neocortical Tet3-mediated accumulation of 5-hydroxymethylcytosine promotes rapid behavioral adaptation. Proc Natl Acad Sci 111: 7120-7125.

Lister R, Mukamel EA. 2015. Turning over DNA methylation in the mind. Front Neurosci 9: 252.

Lubin FD, Roth TL, Sweatt JD. 2008. Epigenetic regulation of BDNF gene transcription in the consolidation of fear memory. J Neurosci 28: 10576-10586.

Ma DK, Jang MH, Guo JU, Kitabatake Y, Chang ML, Pow-Anpongkul N, Flavell RA, Lu B, Ming GL, Song H. 2009. Neuronal activity-induced Gadd $45 \mathrm{~b}$ promotes epigenetic DNA demethylation and adult neurogenesis. Science 323: 1074-1077.

Maddox SA, Watts CS, Schafe GE. 2014. DNA methyltransferase activity is required for memory-related neural plasticity in the lateral amygdala. Neurobiol Learn Mem 107: 93-100.

Martinowich K, Hattori D, Wu H, Fouse S, He F, Hu Y, Fan G, Sun YE. 2003. DNA methylation-related chromatin remodeling in activity-dependent BDNF gene regulation. Science 302: $890-893$.

Miller CA, Sweatt JD. 2007. Covalent modification of DNA regulates memory formation. Neuron 53: 857-869.

Miller CA, Campbell SL, Sweatt JD. 2008. DNA methylation and histone acetylation work in concert to regulate memory formation and synaptic plasticity. Neurobiol Learn Mem 89: 599-603.

Miller CA, Gavin CF, White JA, Parrish RR, Honasoge A, Yancey CR, Rivera IM, Rubio MD, Rumbaugh G, Sweatt JD. 2010. Cortical DNA methylation maintains remote memory. Nat Neurosci 13: 664-666.

Mitchnick KA, Creighton S, O'Hara M, Kalisch BE, Winters BD. 2015. Differential contributions of de novo and maintenance DNA methyltransferases to object memory processing in the rat hippocampus and perirhinal cortex - a double dissociation. Eur J Neurosci 41: 773-786.

Mizuno K, Dempster E, Mill J, Giese KP. 2012. Long-lasting regulation of hippocampal $B d n f$ gene transcription after contextual fear conditioning. Genes Brain Behav 11: 651-659.

Mohammad F, Pandey GK, Mondal T, Enroth S, Redrup L, Gyllensten U, Kanduri C. 2012. Long noncoding RNA-mediated maintenance of DNA methylation and transcriptional gene silencing. Development 139: $2792-2803$

Monsey MS, Ota KT, Akingbade IF, Hong ES, Schafe GE. 2011. Epigenetic alterations are critical for fear memory consolidation and synaptic plasticity in the lateral amygdala. PLoS One 6: e19958.

Moore LD, Le T, Fan G. 2013. DNA methylation and its basic function. Neuropsychopharmacology 38: 23-38.

Morris MJ, Adachi M, Na ES, Monteggia LM. 2014. Selective role for DNMT3a in learning and memory. Neurobiol Learn Mem 115: 30-37.

Nakayama D, Iwata H, Teshirogi C, Ikegaya Y, Matsuki N, Nomura H. 2015. Long-delayed expression of the immediate early gene Arc/Arg3.1 refines neuronal circuits to perpetuate fear memory. J Neurosci 35: 819-830.

Oliveira AM, Hemstedt TJ, Bading H. 2012. Rescue of aging-associated decline in Dnmt3a2 expression restores cognitive abilities. Nat Neurosci 15: $1111-1113$.

Oliveira AM, Hemstedt TJ, Freitag HE, Bading H. 2015. Dnmt3a2: a hub for enhancing cognitive functions. Mol Psychiatry doi: 10.1038/ mp.2015.175

O'Neill J, Senior TJ, Allen K, Huxter JR, Csicsvari J. 2008. Reactivation of experience-dependent cell assembly patterns in the hippocampus. Nat Neurosci 11: 209-215.

Ooi SK, Qiu C, Bernstein E, Li K, Jia D, Yang Z, Erdjument-Bromage H, Tempst P, Lin SP, Allis CD, et al. 2007. DNMT3L connects unmethylated lysine 4 of histone $\mathrm{H} 3$ to de novo methylation of DNA. Nature 448: $714-717$.

Otani J, Nankumo T, Arita K, Inamoto S, Ariyoshi M, Shirakawa M. 2009. Structural basis for recognition of H3K4 methylation status by the DNA methyltransferase 3A ATRX-DNMT3-DNMT3L domain. EMBO Rep 10: $1235-1241$.

Pohodich AE, Zoghbi HY. 2015. Rett syndrome: disruption of epigenetic control of postnatal neurological functions. Hum Mol Genet 24: R10-R16.

Rajasethupathy P, Antonov I, Sheridan R, Frey S, Sander C, Tuschl T, Kandel ER. 2012. A role for neuronal piRNAs in the epigenetic control of memory-related synaptic plasticity. Cell 149: 693-707.

Ramamoorthi K, Fropf R, Belfort GM, Fitzmaurice HL, McKinney RM, Neve RL, Otto T, Lin Y. 2011. Npas4 regulates a transcriptional program in CA3 required for contextual memory formation. Science 334: 1669-1675.

Roth ED, Roth TL, Money KM, SenGupta S, Eason DE, Sweatt JD. 2015. DNA methylation regulates neurophysiological spatial representation in memory formation. Neuroepigenetics 2 : $1-8$.

Rudenko A, Dawlaty MM, Seo J, Cheng AW, Meng J, Le T, Faull KF, Jaenisch R, Tsai LH. 2013. Tet1 is critical for neuronal activity-regulated gene expression and memory extinction. Neuron 79: 1109-1122.

Ryan TJ, Roy DS, Pignatelli M, Arons A, Tonegawa S. 2015. Memory. Engram cells retain memory under retrograde amnesia. Science 348: $1007-1013$

Schubeler D. 2015. Function and information content of DNA methylation. Nature 517: 321-326.

Shukla S, Kavak E, Gregory M, Imashimizu M, Shutinoski B, Kashlev M, Oberdoerffer P, Sandberg R, Oberdoerffer S. 2011. CTCF-promoted RNA polymerase II pausing links DNA methylation to splicing. Nature 479: $74-79$.

Squire LR, Genzel L, Wixted JT, Morris RG. 2015. Memory consolidation. Cold Spring Harb Perspect Biol 7: a021766.

Strahl BD, Allis CD. 2000. The language of covalent histone modifications. Nature 403: $41-45$.

Sultan FA, Wang J, Tront J, Liebermann DA, Sweatt JD. 2012. Genetic deletion of Gadd45b, a regulator of active DNA demethylation, enhances long-term memory and synaptic plasticity. J Neurosci 32: 17059-17066.

Suzuki MM, Bird A. 2008. DNA methylation landscapes: provocative insights from epigenomics. Nat Rev Genet 9: 465-476.

Vaissiere T, Sawan C, Herceg Z. 2008. Epigenetic interplay between histone modifications and DNA methylation in gene silencing. Mutat Res 659: $40-48$.

Zhang Y, Jurkowska R, Soeroes S, Rajavelu A, Dhayalan A, Bock I, Rathert P, Brandt O, Reinhardt R, Fischle W, et al. 2010. Chromatin methylation activity of Dnmt3a and Dnmt3a/3L is guided by interaction of the ADD domain with the histone H3 tail. Nucleic Acids Res 38: 4246-4253.

Zovkic IB, Guzman-Karlsson MC, Sweatt JD. 2013. Epigenetic regulation of memory formation and maintenance. Learn Mem 20: 61-74.

Received April 21, 2016; accepted in revised form July 14, 2016. 


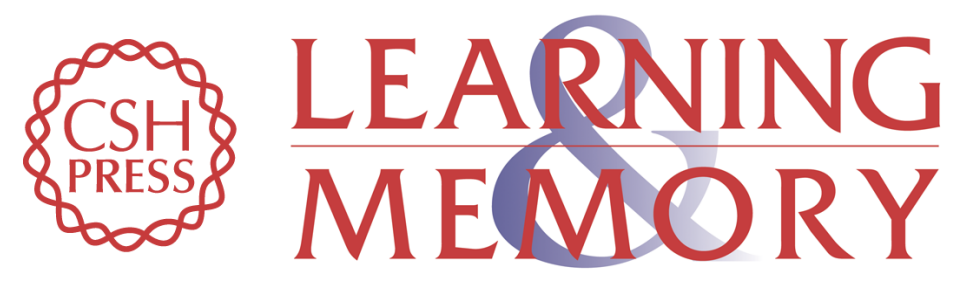

\section{DNA methylation: a permissive mark in memory formation and maintenance}

Ana M.M. Oliveira

Learn. Mem. 2016, 23:

Access the most recent version at doi:10.1101/Im.042739.116

\begin{aligned} & \hline References $\begin{array}{l}\text { This article cites } 77 \text { articles, } 25 \text { of which can be accessed free at: } \\ \text { http://learnmem.cshlp.org/content/23/10/587.full.html\#ref-list-1 }\end{array} \\ & \begin{array}{r}\text { Creative } \\ \text { Commons } \\ \text { License }\end{array} \begin{array}{l}\text { This article is distributed exclusively by Cold Spring Harbor Laboratory Press for the } \\ \text { first } 12 \text { months after the full-issue publication date (see } \\ \text { http://learnmem.cshlp.org/site/misc/terms.xhtml). After } 12 \text { months, it is available under } \\ \text { a Creative Commons License (Attribution-NonCommercial } 4.0 \text { International), as } \\ \text { described at http://creativecommons.org/licenses/by-nc/4.0/. }\end{array} \\ & \begin{array}{c}\text { Receive free email alerts when new articles cite this article - sign up in the box at the } \\ \text { top right corner of the article or click here. }\end{array} \\ & \begin{array}{c}\text { Service } \\ \text { terting }\end{array}\end{aligned}$

